\title{
A quick guide to positioning the transbuccal set
}

\author{
Terzic, A ; Eyrich, G ; Kruse, A ; Lübbers, H T
}

\begin{abstract}
Exact positioning of the transbuccal set can be tricky, especially under aggravating circumstances as present scarring or high body mass index. It may result in multiple skin incisions. This article presents a simple and fast guidance technique that can help in the exact positioning of skin incision and transbuccal set.
\end{abstract}

DOI: https://doi.org/10.1097/SCS.0b013e318232a5ba

Posted at the Zurich Open Repository and Archive, University of Zurich

ZORA URL: https://doi.org/10.5167/uzh-60008

Journal Article

Accepted Version

Originally published at:

Terzic, A; Eyrich, G; Kruse, A; Lübbers, H T (2011). A quick guide to positioning the transbuccal set. Journal of Craniofacial Surgery, 22(6):2295.

DOI: https://doi.org/10.1097/SCS.0b013e318232a5ba 


\title{
Title Page
}

\section{A quick guide for positioning the transbuccal set}

\author{
Authors \\ Andrej Terzic, MD, DMD \\ Hôpitaux Universitaires de Genève \\ Rue Micheli-Du-Crest 24 \\ 1205 Genève - GE \\ Switzerland \\ Gerold Eyrich, MD, DMD \\ Private Practice for Oral and Maxillofacial Surgery \\ Lachen \\ Switzerland \\ Astrid Kruse, MD, DMD \\ Department for Oral and Cranio-Maxillofacial Surgery \\ University Hospital \\ Frauenklinkstrasse 24 \\ $\mathrm{CH}-8091$ Zurich

\section{Corresponding author} \\ Heinz-Theo Lübbers, MD, DMD \\ Consultant \\ Department for Oral and Cranio-Maxillofacial Surgery \\ University Hospital \\ Frauenklinkstrasse 24 \\ $\mathrm{CH}-8091$ Zurich \\ Switzerland \\ Phone: $+4144-255-1111$ \\ FAX: $+4144-255-4179$ \\ Email: Heinz-Theo.Luebbers@usz.ch
}

This work was not funded by any of the following organizations: National Institutes of Health (NIH); Wellcome Trust; Howard Hughes Medical Institute (HHMI); and other(s).

Keywords:

mandibular angle; transbuccal approach; surgical technique 


\section{A quick guide for positioning the transbuccal set}

Especially amongst younger and therefore less experienced surgeons positioning of the incision for the transbuccal approach is an issue. The struggle arises from incorrect judgment. A high body mass index or scarring from prior surgery may additionally reduce soft-tissue flexibility and worsen the situation. The resulting necessity of high pulling forces can result in massive postoperative swelling and depending on the exact location of the approach - sometimes also in transient weakness of facial nerve branches. The need of strong pulling force also reduces the surgeon's manual control, risking screw loss or malposition. However in specific situations exact screw positioning is essential to the outcome of the procedure. ${ }^{1,2}$

Commonly known guidance "tricks" as using the index finger and thumb ${ }^{3}$ or utilizing a surgical forceps ${ }^{4}$ provide only information about where to perform the skin incision, not about the necessary trajectory of the set. However in our experience this is an important factor especially in patients with reduced soft tissue flexibility as described above.

As a solution, we recommend using a thin needle (Figure 1) as described before. ${ }^{5}$ In addition to the initial description by Sittampalam et al. we do not only address the position of the skin incision but also check the trajectory. It can also be checked whether all desired locations are reached by varying the trajectory with one single skin incision. The best position can easily be found.

We recommend using the "needle technique" for situations such as long plates or procedures for the condylar process, as well as for less experienced surgeons in general. The extra time needed for placing the needle is short and costs are obviously negligible. 


\section{CONFLICT OF INTEREST}

Funding: None

Competing interests: None declared

Ethical approval: Not required 


\section{References}

1. Lubbers, HT, Kruse, A, Messmer, P, et al. Precise screw positioning at the mandibular angle: computer assisted versus template coded. J Craniofac Surg $2011 ; 22(2)$ : p. 620-4.

2. Lubbers, HT, Messmer, P, Gratz, KW, et al. Misjudgments at the mandibular angle: freehand versus computer-assisted screw positioning. J Craniofac Surg 2010; $21(4)$ : p. 1012-7.

3. Cienfuegos, R, Cornelius, C-P, Ellis III, E, et al. AO Surgery Reference - CMF - Mandible - Transbuccal system. AO Surgery Reference 2008 2nd June 2011]; Available from:

http://www.aofoundation.org/wps/portal/surgerypopup?contentUrl=/srg/popup/ additional material/91/X20 transbuccal system.jsp\&soloState=seo\&title=\&La nguage=es\&bone=CMF\&segment=Mandible\#6.

4. Lubbers, HT, Gratz, KW, Kruse, A A helpful guide for positioning your transbuccal set. J Oral Maxillofac Surg 2010; 68(8): p. 2028.

5. Sittampalam, G, Rehman, KU, Hanu-Cernat, L A safe and accurate technique for transbuccal incisions. Br J Oral Maxillofac Surg 2007; 45(8): p. 691-2. 


\section{CAPTION}

Figure 1. Exact definition of the ideal trajectory for the transbuccal set

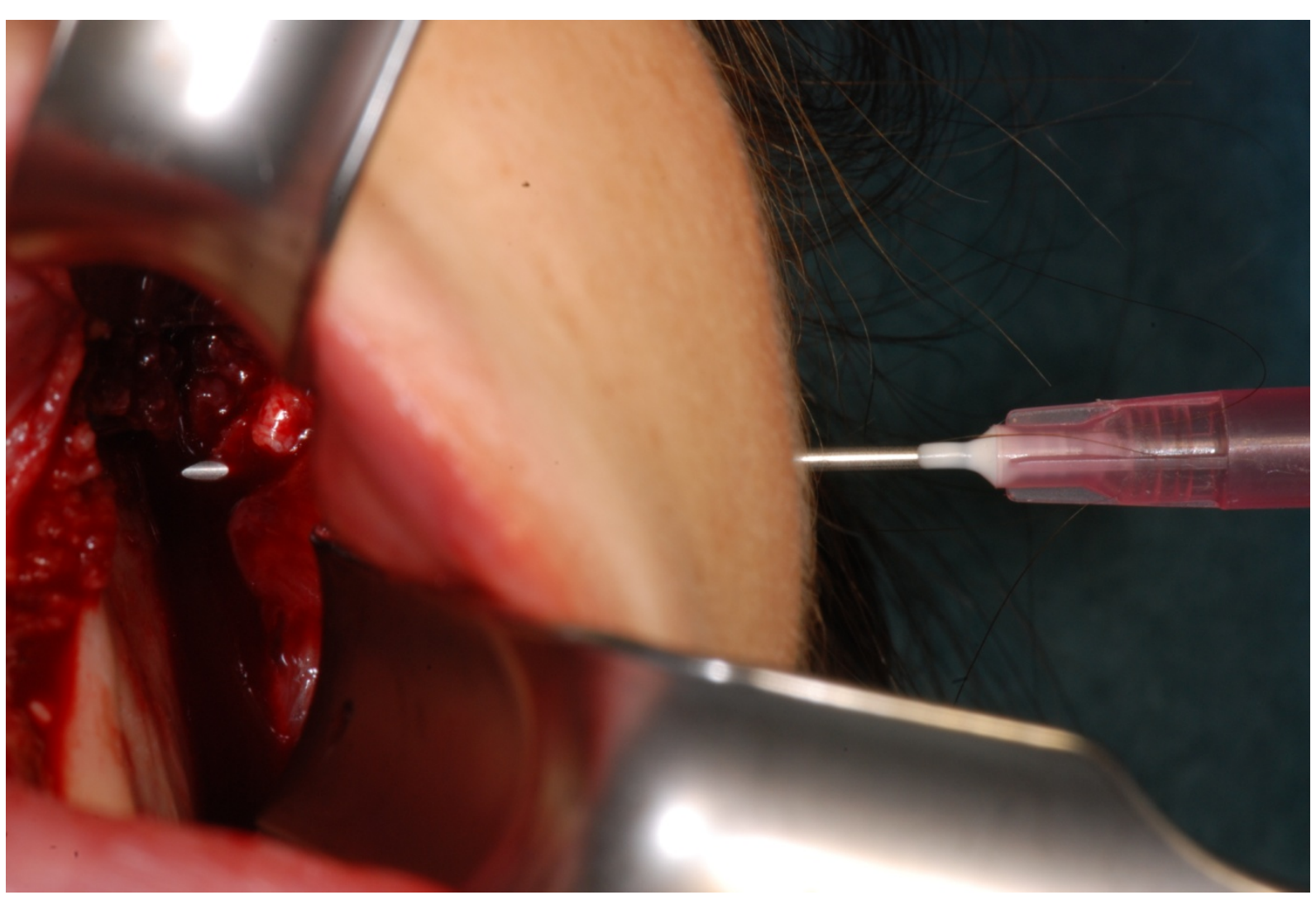

